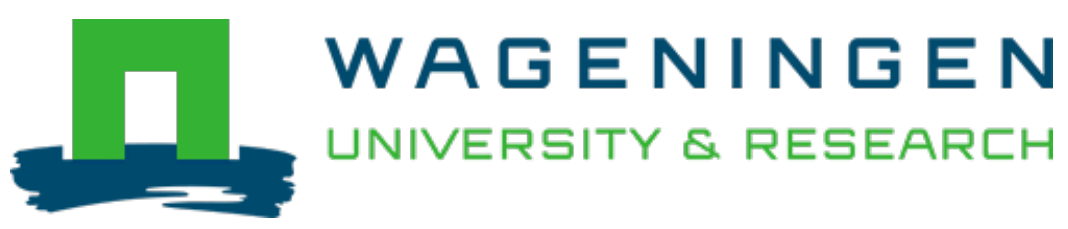

\title{
Application of headspace solid-phase micro-extraction gas chromatography for the assessment of the volatiles profiles of ultra-high temperature hydrolysed- lactose milk during production and storage
}

International Dairy Journal

Bottiroli, Riccardo; Aprea, Eugenio; Betta, Emanuela; Fogliano, Vincenzo; Gasperi, Flavia

https://doi.org/10.1016/j.idairyj.2020.104715

This article is made publicly available in the institutional repository of Wageningen University and Research, under the terms of article $25 \mathrm{fa}$ of the Dutch Copyright Act, also known as the Amendment Taverne. This has been done with explicit consent by the author.

Article 25 fa states that the author of a short scientific work funded either wholly or partially by Dutch public funds is entitled to make that work publicly available for no consideration following a reasonable period of time after the work was first published, provided that clear reference is made to the source of the first publication of the work.

This publication is distributed under The Association of Universities in the Netherlands (VSNU) 'Article $25 \mathrm{fa}$ implementation' project. In this project research outputs of researchers employed by Dutch Universities that comply with the legal requirements of Article 25fa of the Dutch Copyright Act are distributed online and free of cost or other barriers in institutional repositories. Research outputs are distributed six months after their first online publication in the original published version and with proper attribution to the source of the original publication.

You are permitted to download and use the publication for personal purposes. All rights remain with the author(s) and / or copyright owner(s) of this work. Any use of the publication or parts of it other than authorised under article $25 \mathrm{fa}$ of the Dutch Copyright act is prohibited. Wageningen University \& Research and the author(s) of this publication shall not be held responsible or liable for any damages resulting from your (re)use of this publication.

For questions regarding the public availability of this article please contact openscience.library@wur.nl 


\title{
Application of headspace solid-phase micro-extraction gas chromatography for the assessment of the volatiles profiles of ultra-high temperature hydrolysed-lactose milk during production and storage
}

\author{
Riccardo Bottiroli a, b $^{\text {, Eugenio Aprea }}{ }^{\text {a, d, * }}$, Emanuela Betta a , Vincenzo Fogliano ${ }^{c}$, \\ Flavia Gasperi ${ }^{\text {a, d }}$ \\ ${ }^{a}$ Department of Food Quality and Nutrition, Research and Innovation Centre, Fondazione Edmund Mach, via E. Mach 1, 38010 San Michele all'Adige, \\ $T N$, Italy \\ b Department of Agriculture and Food Science, University of Naples, Federico II, 80055, Portici, NA, Italy \\ ${ }^{c}$ Food Quality \& Design Group, Wageningen University, PO Box 8129, 6700, EV Wageningen, the Netherlands \\ ${ }^{\mathrm{d}}$ Center Agriculture Food Environment University of Trento/Fondazione Edmund Mach, via E. Mach 1, 38010, San Michele all'Adige, TN, Italy
}

\section{A R T I C L E I N F O}

\section{Article history:}

Received 28 November 2019

Received in revised form

18 March 2020

Accepted 18 March 2020

Available online 3 April 2020

\begin{abstract}
A B S T R A C T
UHT hydrolysed-lactose milk (HLM) is prone to chemical changes, giving rise to off-flavours in the product. To investigate this better, headspace solid-phase micro-extraction gas chromatography (HSSPME/GC-MS) was applied to monitor the volatiles profile of HLM during production and shelf-life. Optimum extraction conditions for volatiles were explored, focussing on compounds affecting milk aroma. This study is the first investigating industrial scale manufacturing under controlled conditions, allowing direct associations between specific reactions and changes in milk volatiles. The effect of UHT treatment on milk flavour was shown, while the lactase, potentially containing undesirable proteases and odours, did not alter the milk "volatilome" after addition. Commercial samples exhibited different trends in the volatiles along the shelf-life due to differences in production systems, lactase purity and packaging. Merging all results, HS-SPME/GC-MS successfully mapped the phenomena causing modifications in the volatiles profile of UHT HLM at each step of the product life-cycle.
\end{abstract}

(C) 2020 Elsevier Ltd. All rights reserved.

\section{Introduction}

Lactose is the most abundant carbohydrate found in milk (Ingram, Mulcare, Itan, Thomas, \& Swallow, 2009) and its proper digestion depends on the presence of lactase ( $\beta-1,4$-galactosidase) in the human gut. If not hydrolysed into glucose and galactose, lactose passes through the gastrointestinal tract inducing the production of metabolites (e.g., methane, carbon dioxide and hydrogen) that likely cause diarrhoea, stomach pain, flatulence and constipation (Corgneau et al., 2017; Leonardi, Gerbault, Thomas, \& Burger, 2012). As a result, dairy industries increased the launch of low lactose milk products, as they represent a simple and handy solution against lactose malabsorption (Troise et al., 2016).

\footnotetext{
* Corresponding author. Tel.: +39 0461615750.

E-mail address: eugenio.aprea@fmach.it (E. Aprea).
}

Addition of free soluble lactase in the milk is the most popular process applied in industry for the production of hydrolysed lactose milk (HLM) (Jelen \& Tossavainen, 2003). Alternative processes include acid hydrolysis, membrane reactors, immobilised systems for enzymatic hydrolysis, and cellular extract from lactobacilli (Harju, Kallioinen, \& Tossavainen, 2012). The addition of free soluble lactase into the milk can be performed at refrigerated conditions before the ultra-high temperature (UHT) treatment, namely following the "in batch" production system (Troise et al., 2016). The process ascertains that the lactase is inactivated before the product is sold (Dekker, Koenders, \& Bruins, 2019). On the other hand, it exposes glucose and galactose, which are more sensitive to Maillard reaction than lactose (Evangelisti, Calcagno, Nardi, \& Zunin, 1999), to high temperature. Recently, a more versatile technology in which the lactase is added in each milk package aseptically after the thermal treatment ("in pack" production system) has been developed (Harju et al., 2012; Troise et al., 2016). This allows the 
employment of lower concentrations of lactase, reducing the overall costs of production (Troise et al., 2016). UHT HLM produced by "in batch" and "in pack" technology have many features in common, but differ mainly by the presence of active lactase during the shelf-life of the latter. This aspect is of particular interest because, when the lactase is purified from microorganisms, some secondary proteases are conveyed into the final preparation resulting in commercial lactases having different purity (Nielsen et al., 2018).

This proteolytic side activity favours the release of free amino acids and peptides in the milk, which may push the proceeding of the Maillard reaction and the development of off-flavours during storage (Jansson et al., 2014c; Troise et al., 2016). When the lactase is added "in batch", these defects can be modulated as proteolytic side activity is partially or totally annulled by the UHT treatment (Dekker et al., 2019; Tossavainen \& Kallioinen, 2007). In contrast, when the lactase is added "in pack", no thermal inactivation takes place, proteolysis and off-flavour development can therefore proceed and, if not properly controlled, the final product quality can deteriorate faster (Nielsen et al., 2018; Troise et al., 2016).

For the assessment of chemical modifications that may occur during the shelf-life of milk, analysis of the volatile organic compounds (VOCs) profile is an attractive approach. VOCs can reveal chemical modifications at early stages before the concentration of the developed compounds reach the human perception threshold, thus tainting the product. Among the available analytical techniques, headspace solid phase micro-extraction (HS-SPME) coupled to gas chromatography-mass spectrometry (GC-MS) has been applied for detecting the volatile profiles of many dairy products such as fermented milk, cheese and butter (Aprea et al., 2016; Condurso, Verzera, Romeo, Ziino, \& Conte, 2008; Endrizzi et al., 2012; Povolo \& Contarini, 2003). HS-SPME is a simple solventfree method, which is less time-consuming and requires less sample handling compared with other extraction techniques applied in food science (González-Córdova \& Vallejo-Cordoba, 2001; Vazquez-Landaverde, Velazquez, Torres, \& Qian, 2005).

In this context, the aim of the present work was to set the optimal extraction parameters for a HS-SPME/GC-MS methodology and apply it to study the volatile profiles of HLM. The optimised method was applied in two case studies, namely the formation of VOCs during production of UHT HLM by "in batch" system and monitoring the evolution of the VOCs in different commercial UHT HLMs during storage. To the best of our knowledge, this is the first work in which a HS-SPME/GC-MS methodology is optimised and applied for the assessment of the VOCs profiles of HLMs along production and during storage.

\section{Material and methods}

\subsection{Chemicals}

Sodium chloride, 4-methyl-2-pentanone (internal standard with purity $\geq 99 \%$ ), 2-methylbutanal (purity $\geq 95 \%$ ) and 3- methylbutanal (purity $\geq 97 \%$ ) were purchased from Sigma-Aldrich (Steinheim, Germany).

\subsection{Ultra-high temperature (UHT) hydrolysed-lactose milk samples}

For the validation of the optimised HS-SPME conditions, the VOCs profiles of different UHT HLM samples were analysed. An overview of the milk samples is reported in Table 1. Samples produced by "in batch" technology were collected at the following production steps: before addition of the lactase ( $\mathrm{preH}$ ), at the end of the lactose hydrolysis (postH) and after the direct UHT processing (postUHT). Production details were as reported by Troise et al. (2016) for the "in batch" production system. Samples were taken from three consecutive batches of production, all performed under the same operating conditions, as an estimation of the initial milk variability. The same commercial lactase preparation was used for production: according to the technical sheet provided by the supplier, the lactase was extracted from Kluyveromyces lactis and had an average enzymatic activity $\geq 5000 \mathrm{NLU} \mathrm{g}^{-1}$.

For the shelf-life simulation study, three different semiskimmed UHT HLM (HLM1, HLM2, HLM3), were purchased from supermarkets in February 2018. A 4-month (120 days) storage was then performed, keeping the samples in a climate chamber at room temperature $\left(20{ }^{\circ} \mathrm{C}\right)$ under controlled conditions. Samples were taken out from the climate chamber every 30 days and stored at $-80{ }^{\circ} \mathrm{C}$ until analysis. The time zero of the study was established within one week after the production date. At the moment of the purchase, however, the production date of HLM3 was different from that of HLM1 and HLM2 and it was not possible to sample HLM3 from the beginning of the shelf-life. To deal with this difference, sampling of HLM3 started after 30 days of storage. The commercial UHT HLMs differed in terms of packaging and system of production used by producers (Table 1 ).

\subsection{Selection of SPME coating phase and optimisation of the extraction parameters}

Based on literature and previous experience (Aprea, Gasperi, Betta, Sani, \& Cantini, 2018) a three-phasic (DVB-CarboxenPDMS) SPME fibre was selected to grant the widest coverage of analytes. $\mathrm{A}^{3}$ full factorial design with one centred point was applied to investigate the effect of sample size $(5-10 \mathrm{~mL})$, extraction time (30-90 $\mathrm{min})$ and addition of salts $(0 \%-30 \%, \mathrm{w} / \mathrm{w}, \mathrm{NaCl})$ on the amount of VOCs extracted by the SPME fibre. Full factorial design is an orthogonal experimental design method in which all the factors are combined simultaneously (Aprea et al., 2011). A central point is often included in the design to represent the average between the low and high level of the combined factors. In our case, the central point was $7.5 \mathrm{~mL}$ sample size, 60 min extraction time, $15 \%(\mathrm{w} / \mathrm{w}) \mathrm{NaCl}$. Temperature of the incubation and extraction were fixed at $40{ }^{\circ} \mathrm{C}$ as a compromise to favour the volatilisation of the VOCs without inducing chemical modification of the milk during the analysis. For the optimisation of the procedure,

Table 1

Overview of the milk samples analysed for the validation of the developed HS-SPME/GC-MS methodology ${ }^{\mathrm{a}}$.

\begin{tabular}{|c|c|c|c|c|c|}
\hline Case study & Sample acronym & Sample description & Process of production & Packaging & Lactose content (g $100 \mathrm{~mL}^{-1}$ milk) \\
\hline I & preH & Pasteurised milk sampled before lactose hydrolysis & In-batch & - & $\mathrm{Nd}$ \\
\hline I & postH & Pasteurised HLM sampled after lactose hydrolysis & In-batch & - & $<0.1$ \\
\hline I & postUHT & UHT HLM sampled after heat sterilisation & In-batch & - & $<0.1$ \\
\hline II & HLM1 & Commercial UHT HLM & In-batch & Cardboard carton & $<0.1$ \\
\hline II & HLM2 & Commercial UHT HLM & In-batch & HDPE & $<0.1$ \\
\hline II & HLM3 & Commercial UHT HLM & In-pack & Cardboard carton & $<0.1$ \\
\hline
\end{tabular}

a Case studies are those in which VOCs were evaluated (I) at different steps (preH, before lactose hydrolysis; postH, after lactose hydrolysis; postUHT, after UHT treatment) during the "in batch" production system and (II) in three different commercial samples (HLM1, HLM2, and HLM3; all semi-skimmed) stored at $20{ }^{\circ} \mathrm{C}$ for 120 days. 
we considered as target the total area of the identified integrated peaks. The sample used during the optimisation steps was a commercial UHT HLM having 66 days of shelf-life.

\subsection{Sample analysis}

Once the optimal conditions for the HS-SPME were defined, the VOCs profiles of different UHT HLM during "in batch" production and storage were determined. The analysis was performed according to Bergamaschi et al. (2015). Measurements were performed using $20 \mathrm{~mL}$ glass vials with 4-methyl-2-pentanone as internal standard. For the aim of the present research absolute quantification by calibration curves was not necessary, thus the internal standard was used also to normalise the data (semiquantitative results).

Frozen HLM samples were thawed at room temperature. Volatile compounds were first extracted at $40{ }^{\circ} \mathrm{C}$ with the $2 \mathrm{~cm}$ DVBCarboxen-PDMS SPME fibre and then desorbed at $250{ }^{\circ} \mathrm{C}$ in the injector port of a GC interfaced with a mass detector operating in an electron ionisation mode (internal ionisation source; $70 \mathrm{eV}$ ) with a scan range from 33 to $300 \mathrm{~m} / z$ (GC Clarus 500, PerkinElmer, Norwalk, CT, USA). Procedure phases were automatically managed using an auto-sampling system (CTC combiPAL, CTC Analysis AG, Zwingen, Switzerland). Separation was achieved on a HP-Innowax fused-silica capillary column $(30 \mathrm{~m}, 0.32 \mathrm{~mm}$ inner diameter, $0.5 \mu \mathrm{m}$ film thickness; Agilent Technologies, Palo Alto, CA, USA). The temperature program was set progressively as follows: $40{ }^{\circ} \mathrm{C}$ for $3 \mathrm{~min}, 180^{\circ} \mathrm{C}$ for $6 \mathrm{~min}$ at $4{ }^{\circ} \mathrm{C} \mathrm{min}^{-1}, 220^{\circ} \mathrm{C}$ for $3 \mathrm{~min}$ at $3{ }^{\circ} \mathrm{C}$ $\mathrm{min}^{-1}$. Helium (flow rate equal to $2 \mathrm{~mL} \mathrm{~min}^{-1}$ ) was chosen as carrier gas. The transfer line temperature was kept at $220^{\circ} \mathrm{C}$. Linear retention indices (LRI) were calculated under the same chromatographic conditions, injecting C7-C30 n-alkane series (Supelco, Bellefonte, PA, USA). Compounds were identified using the mass spectra matching the NIST-2014/Wiley 7.0 libraries and comparing the calculated LRI with those available from literature.

\subsection{Data analysis}

For optimising the HS-SPME conditions, the total peak area of the identified and verified volatile compounds was considered. Differences in the volatile profiles were investigated by analysis of the variance (ANOVA), and Tukey post-hoc test. A $P \leq 0.05$ was chosen as threshold for significant differences. Principal component analysis (PCA) was performed, on the log-transformed GC data scaled to unit variance, to explore the spatial distribution of the samples in both case studies. Statistical analysis of the results was performed with the software package STATISTICA 13.3 (StatSoft, Inc., Tulsa, OK, USA) and the R packages (version 3.3.3) FactoMineR and factoextra.

\section{Results and discussion}

\subsection{Optimisation of headspace solid-phase microextraction (HS- SPME) conditions}

The effect of each tested parameter by means of the $2^{3}$ full factorial design was reported in the form of a Pareto chart in Fig. 1a, whereas Fig. 1b profiles the surface plot of the outcome as function of extraction time and sample size. In the Pareto chart, the impact of the investigated variables on a response is displayed in the form of a bar chart. The lengths of the bars are proportional to the relative standardised effect. If a bar exceeds the vertical line (corresponding to the $95 \%$ confidence interval) the effect can be considered statistically significant. From Fig. 1a, addition of $30 \%$ (w/w) $\mathrm{NaCl}$ was the most significant factor and affected negatively the HS-SPME performance. The combination of this parameter with the sample size (volume of milk in $20 \mathrm{~mL}$ vials) was also significant, even though at much lower extent.

In gas chromatography, salting out effect is widely exploited to improve the extraction efficiency in the headspace (Yang \& Peppard, 1994). Addition of monovalent and bivalent salts increases the ionic strength of the solution with a consequent decrease of solubility of those non-polar compounds, which tend to be pushed towards the headspace (Fiorini, Pacetti, Gabbianelli, Gabrielli, \& Ballini, 2015). The salting out effect has been previously employed for better extraction of volatiles from milk (González-Córdova \& Vallejo-Cordoba, 2001; Marsili, 1999). González-Córdova \& Vallejo-Cordoba, 2001 reported higher levels of acids extraction depending on the solubility of the compounds.

This finding was in line with our results: when 90 min of extraction time was applied, the addition of $30 \%(\mathrm{w} / \mathrm{w}) \mathrm{NaCl}$ in the samples ended up in an increase of octanoic acid detection up to 92\%. Also decanoic acid extraction increased but at lower extent, due to its relative lower solubility in water compared with octanoic acid (Supplementary material Fig. S1). Nevertheless, VOCs with different polarity behaved differently in response to the HS-SPME conditions, an aspect particularly relevant when performing VOCs profiling analysis. For examples, in our study the addition of salts suppressed the extraction of some compounds of interest for UHT HLMs, such as ketones and dimethyl disulphide (DMDS).

Methyl ketones and DMDS give a strong contribution to the overall sensory profile of UHT milk (Valero, Villamiel, Miralles, Sanz, \& Martínez-Castro, 2001) and, therefore, an adequate sensitivity of the extraction step is necessary. In particular, DMDS underlies secondary pathways of Maillard reaction, which occur more extensively in UHT HLM than regular UHT milk. Thus, for further investigation of the optimum, salt was removed from the experimental design before constructing the surface plot (Fig. 1b). Our approach differed from some previous publications substantially by the way how the impact of the VOCs on the milk aroma was considered. Authors working on similar products (e.g., regular pasteurised and UHT milk) preferred an optimisation of the SPME performance focused only on a sole class of molecules related to a specific sensory defect; an example is the work published by González-Córdova and Vallejo-Cordoba (2001) where only shortchain fatty acids extraction was considered.

In UHT HLM sensory defects can arise from a multitude of factors, which make it reasonable to extend the investigation of the optimum to a broader range of VOCs. A similar strategy was employed by Vazquez-Landaverde et al. (2005) for raw, pasteurised and UHT milk, although the addition of $\mathrm{NaCl}$ was not considered in the optimisation step of the SPME fibre. In Fig. 1b. The best conditions for the extraction by the HS-SPME fibre are displayed by the dark red region of the plot, which corresponds to a total area count of the peaks higher than $1.9 \times 10^{8}$. Optimal conditions for each class of compounds (ketones, aldehydes, organic acids, phenolic compounds, aromatic compounds, sulphur compounds and lactones) are reported in Supplementary material Table S2. All these conditions should be considered valid solely in the tested range when performing a semi-quantitative profile analysis of the VOCs in HLM.

Removing salt from the design resulted also in an absence of significant factors in the ranges we considered here, allowing a flexible rearrangement of the conditions. Accordingly, $60 \mathrm{~min}$ of extraction time was chosen as best compromise to align the SPME method with the GC-MS run and to shorten the total time of analysis. Next, the selected conditions (sample size $5 \mathrm{~mL}$; extraction time $60 \mathrm{~min} ; 0 \%, \mathrm{w} / \mathrm{w}, \mathrm{NaCl}$ ) were applied to evaluate the formation of VOCs in different steps of "in batch" production as well as to spot different VOCs profiles in commercial UHT HLMs stored at $20^{\circ} \mathrm{C}$ for 120 days. 

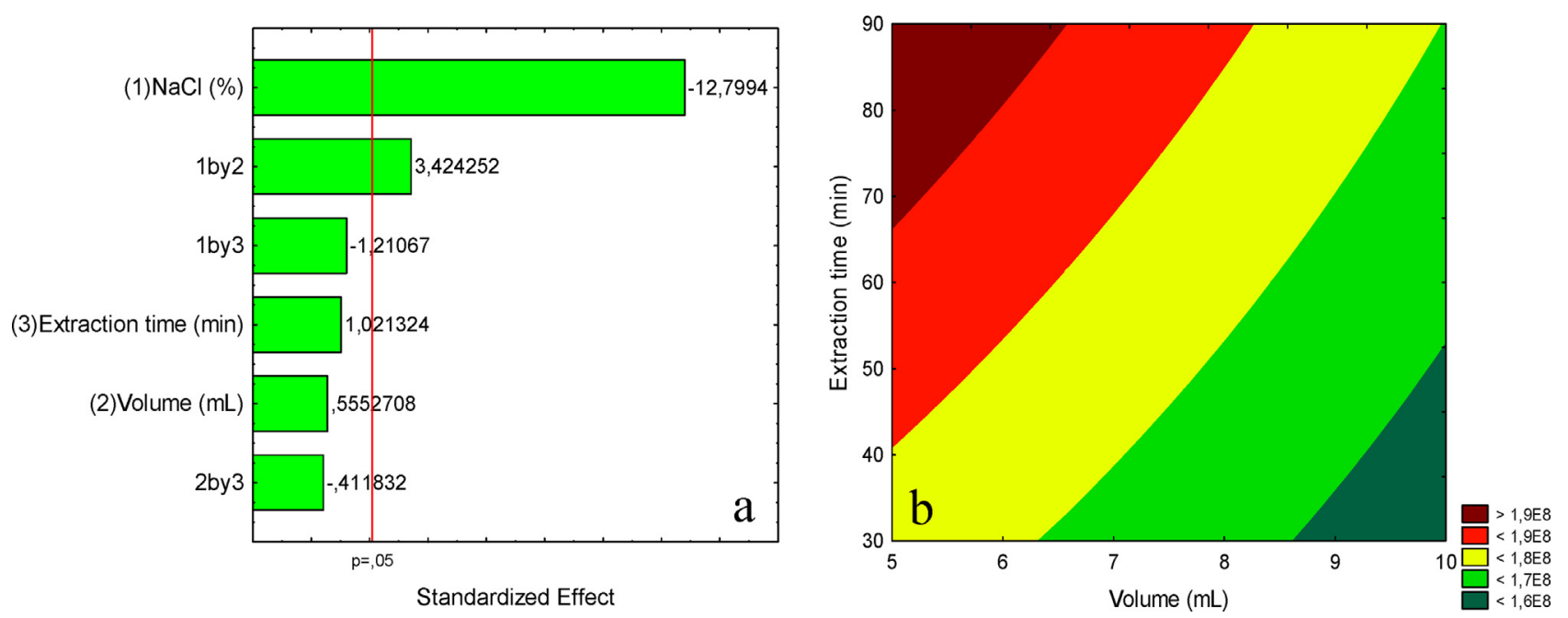

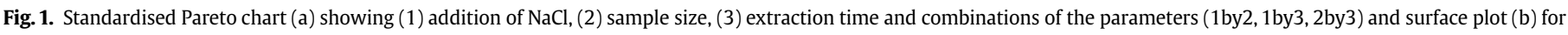
total peak area as function of extraction time and sample volume. $\mathrm{NaCl}$ was set as $0 \%(\mathrm{w} / \mathrm{w})$.

\subsection{Volatiles profile of UHT HLM during "in batch" production system}

A total of 17 compounds were identified and semi-quantified from the headspace of the HLM samples taken during "in batch" production (Table 2). PCA was applied to reveal pattern in the dataset. In Fig. 2, the bi-plot of the 1 st and the 2nd principal component (Dim1 and Dim2, accounting respectively for $39.0 \%$ and $16.6 \%$ of the total variance) are plotted. The postUHT samples were characterised by positive values for Dim1, which clearly separate them from the rest of the samples. According to the loadings, differences in methyl-ketones concentrations were responsible for the separation of the postUHTs. Such indication was further validated by the analysis of the variance, where most of the methyl-ketones were significantly higher in the postUHTs. An opposite trend was shown by 2-butanone, which registered lower values after the UHT sterilisation. Explanations of the observation might come from the

Table 2

Volatile compound profile of preH, postH and postUHT in the three consecutive replicates of production from which the samples were collected.

\begin{tabular}{lllll}
\hline Volatile compound & RI & PreH & PostH & PostUHT \\
\hline 2-Butanone & 909 & $13.44^{\mathrm{a}} \pm 4.74$ & $12.92^{\mathrm{a}} \pm 1.96$ & $1.28^{\mathrm{b}} \pm 0.36$ \\
2-Pentanone & 987 & $0.79 \pm 0.14$ & $0.68 \pm 0.11$ & $0.78 \pm 0.13$ \\
Dimethyldisulphide & 1085 & nd & nd & $0.41^{\mathrm{b}} \pm 0.49$ \\
Hexanal & 1099 & $8.76 \pm 7.66$ & $3.94 \pm 2.64$ & $3.55 \pm 3.13$ \\
Ethyl-benzene & 1131 & $0.18^{\mathrm{a}} \pm 0.07$ & $0.11^{\mathrm{a}} \pm 0.03$ & $2.02^{\mathrm{b}} \pm 1.33$ \\
2-Heptanone & 1193 & $4.69^{\mathrm{a} . \mathrm{b}} \pm 2.72$ & $4.16^{\mathrm{a}} \pm 2.63$ & $7.32^{\mathrm{b}} \pm 1.78$ \\
2-Nonanone & 1397 & $1.09^{\mathrm{a}} \pm 0.66$ & $1.18^{\mathrm{a}} \pm 0.83$ & $2.11^{\mathrm{b}} \pm 0.18$ \\
Benzaldehyde & 1533 & nd & $n \mathrm{nd}^{\mathrm{a}} \pm 0.04$ & $0.23^{\mathrm{b}} \pm 0.04$ \\
2-Undecanone & 1607 & $0.26^{\mathrm{a}} \pm 0.14$ & $0.25^{\mathrm{a}} \pm 0.15$ & $0.43^{\mathrm{b}} \pm 0.11$ \\
Butyrolactone & 1637 & $0.15 \pm 0.03$ & $0.14 \pm 0.03$ & $0.16 \pm 0.02$ \\
2-Tridecanone & 1819 & $0.02^{\mathrm{a}} \pm 0.02$ & $0.02^{\mathrm{a}} \pm 0.02$ & $0.09^{\mathrm{b}} \pm 0.03$ \\
Hexanoic acid & 1900 & $1.12^{\mathrm{a}} \pm 0.40$ & $1.06^{\mathrm{a}} \pm 0.39$ & $0.63^{\mathrm{b}} \pm 0.22$ \\
Dimethyl sulphone & 1910 & $2.96^{\mathrm{a}} \pm 0.64$ & $3.02^{\mathrm{a}} \pm 1.66$ & $1.57^{\mathrm{b}} \pm 0.34$ \\
Phenol & 2020 & $0.24 \pm 0.05$ & $0.23 \pm 0.06$ & $0.26 \pm 0.04$ \\
Octanoic acid & 2144 & $1.75^{\mathrm{a}} \pm 0.68$ & $1.75^{\mathrm{a}} \pm 0.44$ & $1.08^{\mathrm{b}} \pm 0.33$ \\
Nonanoic acid & 2215 & $0.18 \pm 0.22$ & $0.19 \pm 0.16$ & $0.36 \pm 0.40$ \\
Decanoic acid & 2307 & $0.89 \pm 0.28$ & $0.92 \pm 0.33$ & $1.03 \pm 0.37$ \\
\hline
\end{tabular}

a Abbreviations: RI, linear retention index; preH, postH, postUHT, the production steps at which the milk was sampled along the "in batch" production system, namely before lactose hydrolysis, after lactose hydrolysis and after UHT treatment, respectively. Compounds were tentatively identified matching the NIST-2014/Wiley 7.0 libraries. Values ( $\mu$ g IS $\mathrm{L}^{-1}$ ) are means \pm standard deviation (nd, not detected); means within a row with different superscript letters differ significantly $(P<0.05)$. high volatility of the compound resulting in its stripping during degassing of the UHT process (Contarini et al., 1997).

Methyl-ketones are a thermal-induced class of compounds, whose formation is related to both $\beta$-oxidation of fatty acids and decarboxylation of $\beta$-keto acids (Jansson et al., 2014a). In this context, our study gave further confirmation about the increase of methyl-ketones in milk upon heating, previously reported by Contarini et al. (1997). Furthermore, focusing on the preH and postH samples, absence of significant differences in the VOCs profiles was reported. Accordingly, VOCs were not produced in significant amounts when lactase was added into the milk and during the hydrolysis of lactose that, according to the "in batch" production protocol, occurs at refrigerated conditions and lasts approximately in one day (Dekker et al., 2019; Troise et al., 2016).

\subsection{Volatiles profile during storage of commercial HLMs at $20^{\circ} \mathrm{C}$}

HS-SPME/GC-MS analysis was further conducted on three different commercial samples stored for 120 days at $20{ }^{\circ} \mathrm{C}$ and sampled every 30 days. In total, 28 VOCs were identified. The range of concentration (expressed as equivalent of internal standard) was between $<0.01$ and $14.85 \mu \mathrm{g} \mathrm{L}^{-1}$ milk and the profiles were similar to those previously determined by other authors working on the topic (Jansson et al., 2014b; Troise et al., 2016). PCA was again performed. The first three principal components (PC1, PC2 and PC3) explained the $51.50 \%$ of the total variance and the best visualisation was achieved plotting the PC1 and the PC2 (Fig. 3). Separation of the three hydrolysed-lactose milks was observed (Fig. 3b) and different concentrations of ketones, aldehydes and organic acids seemed to be the main responsible for the separation (Fig. 3a).

HLM3 was well described by 2-pentanone, 2-heptanone, 2nonanone, 2-undecanone, 2-tridecanone, benzaldehyde and hexanal, whereas 2-methylbutanal, butanoic acid, hexanoic acid, octanoic acid, decanoic acid, ethyl-benzene and 2-propanone differentiated HLM2 from the other two commercial milk samples. The different technology employed for the manufacturing ("in batch" for HLM1 and HLM2, "in pack" for HLM3) can partially explain the results. Some information about the analysed UHT HLMs were, however, unavailable. For example, we did not know the type and the purity of the lactase preparation used by suppliers.

Bioscience companies sell lactases having different purities with respect to the level of residual proteolytic activity and (in some 


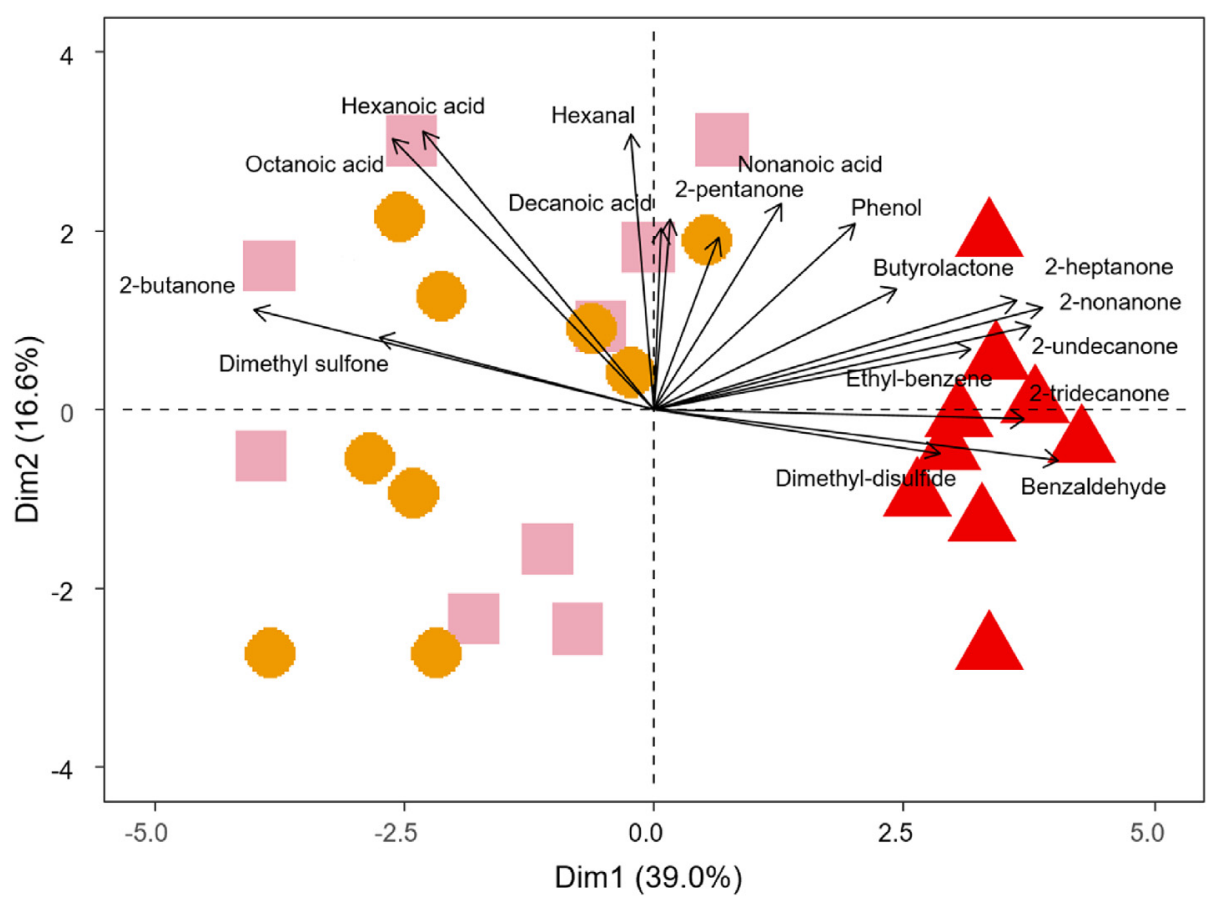

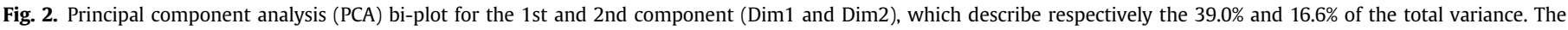

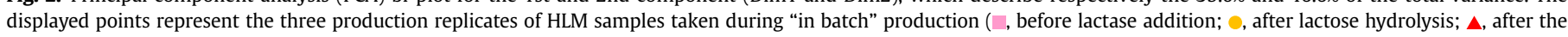
UHT treatment).
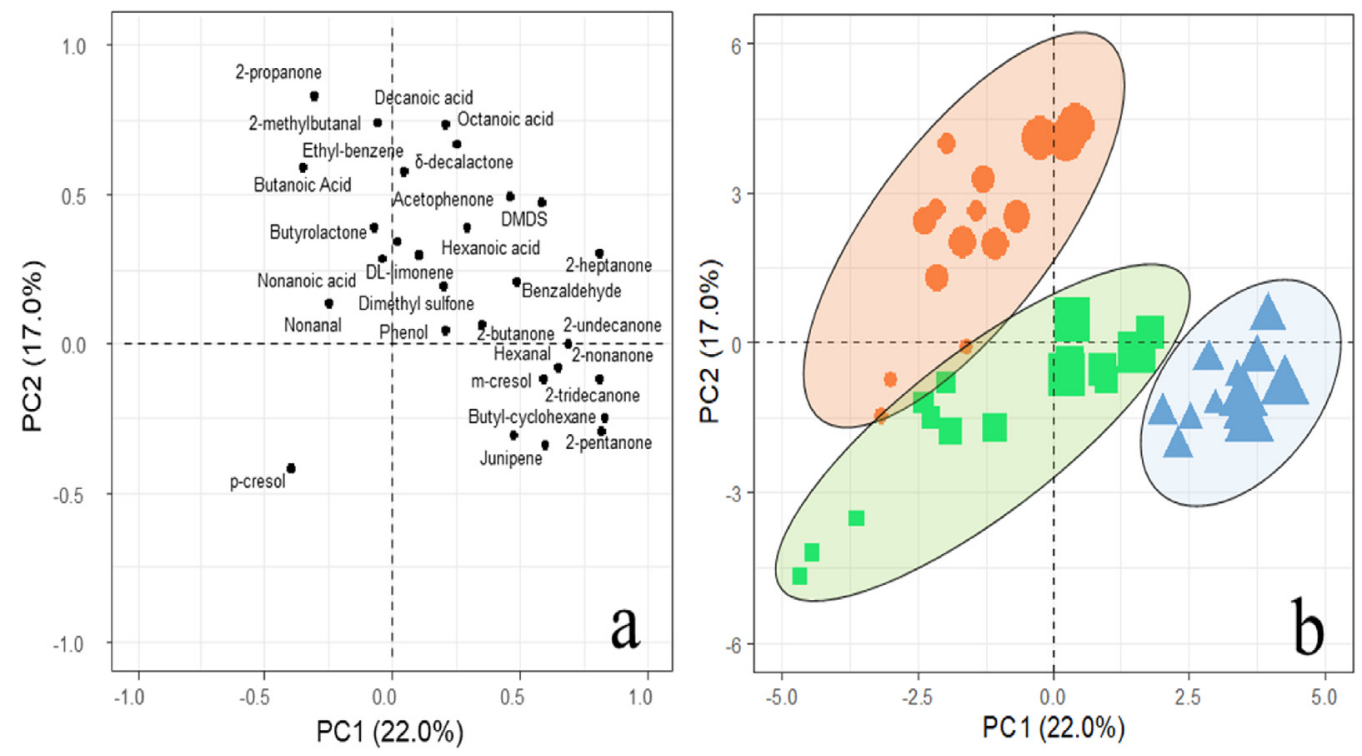

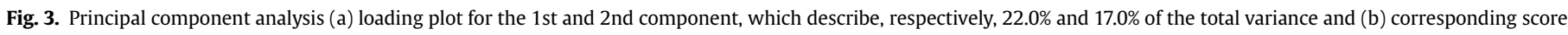

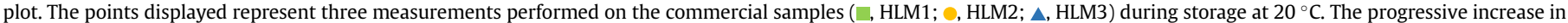
dots size indicates the proceeding of the storage $(0,30,60,90,120$ days).

cases) residual arysulphatase activity in the preparation. Lactase purity was previously reviewed as crucial for defining the quality and the stability of UHT HLM (Nielsen et al., 2018; Troise et al., 2016). In particular, Troise et al. (2016) emphasised the importance of this aspect when performing "in pack" production. Although a direct comparison of the "in batch" and "in pack" production system has not been published yet, researchers believe that the quality of "in batch" UHT HLM is independent from the purity of lactase. Interestingly, HLM1 and HLM2 were clearly separated in Fig. 3b, although both were produced by "in batch" system. In this case, the different packaging material (paperboard carton for HLM1 and HDPE for HLM2) may have contributed to the pattern. Overall, the different VOCs profiles of HLM1, HLM2 and HLM3 showed by the explorative PCA were the results of several variables (e.g., production system, lactase purity and packaging). Nevertheless, we can conclude that the chosen SPME conditions were appropriate for a sensitive detection of the VOCs independently from the sources of the variation.

Table 3 reports the quantification of the identified VOCs: results are semi-quantitative and must be considered to highlight trends 
Table 3

Volatile compound profiles of HLM1, HLM2 and HLM3 as a function of storage time ${ }^{\mathrm{a}}$.

\begin{tabular}{|c|c|c|c|c|c|c|c|c|c|c|c|c|c|c|c|c|c|c|c|}
\hline \multirow[t]{2}{*}{ Volatile compound } & \multirow[t]{2}{*}{ RI } & \multicolumn{5}{|l|}{ HLM1 } & \multirow[t]{2}{*}{ Trend } & \multicolumn{5}{|l|}{ HLM2 } & \multirow[t]{2}{*}{ Trend } & \multicolumn{5}{|c|}{ HLM3 } & \multirow[t]{2}{*}{ Trend } \\
\hline & & 0 & 30 & 60 & 90 & 120 & & 0 & 30 & 60 & 90 & 120 & & 0 & 30 & 60 & 90 & 120 & \\
\hline \multicolumn{20}{|l|}{ Ketones } \\
\hline 2-Propanone & 822 & nd & nd & nd & nd & nd & & $\mathrm{nd}^{\mathrm{a}}$ & $5.29^{\mathrm{b}}$ & $7.23^{c}$ & $3.82^{\mathrm{d}}$ & $3.94^{\mathrm{d}}$ & $\uparrow$ & $\mathrm{nm}$ & nd & nd & nd & nd & \\
\hline 2-Butanone & 909 & $3.78^{\mathrm{a}}$ & $n d^{b}$ & $1.86^{\mathrm{c}}$ & $4.77^{\mathrm{d}}$ & $3.92^{\mathrm{a}}$ & & $2.84^{\mathrm{a}}$ & $2.36^{\mathrm{a}}$ & $1.09^{\mathrm{b}}$ & $3.26^{\mathrm{a}}$ & $2.95^{\mathrm{a}}$ & & $\mathrm{nm}$ & $6.01^{\mathrm{a}}$ & $4.74^{\mathrm{a}, \mathrm{b}}$ & $3.70^{\mathrm{b}}$ & $5.74^{\mathrm{a}}$ & \\
\hline 2-Pentanone & 987 & 2.99 & 2.39 & 2.88 & 2.45 & 3.27 & & $0.47^{\mathrm{a}}$ & $1.34^{\mathrm{b}}$ & $1.33^{\mathrm{b}}$ & $1.72^{\mathrm{b}}$ & $2.95^{\mathrm{c}}$ & $\uparrow$ & $\mathrm{nm}$ & $2.33^{\mathrm{a}}$ & $2.89^{\mathrm{a}}$ & $5.87^{\mathrm{b}}$ & $7.85^{\mathrm{c}}$ & $\uparrow$ \\
\hline 2-Heptanone & 1193 & $2.44^{\mathrm{a}}$ & $5.65^{\mathrm{b}}$ & $7.63^{\mathrm{b}}$ & $7.84^{\mathrm{b}}$ & $10.14^{\mathrm{c}}$ & $\uparrow$ & $3.38^{\mathrm{a}}$ & $6.93^{\mathrm{b}}$ & $7.11^{\mathrm{b}}$ & $8.57^{\mathrm{b}}$ & $9.61^{\mathrm{b}}$ & $\uparrow$ & $\mathrm{nm}$ & $8.07^{\mathrm{a}}$ & $11.05^{\mathrm{b}}$ & $13.61^{\mathrm{b}, \mathrm{c}}$ & $14.85^{\mathrm{c}}$ & $\uparrow$ \\
\hline 2-Nonanone & 1397 & 1.17 & 1.09 & 1.67 & 2.45 & 2.17 & & 1.10 & 1.14 & 1.13 & 1.73 & 1.49 & & $\mathrm{~nm}$ & 1.85 & 2.10 & 2.60 & 2.35 & \\
\hline 2-Undecanone & 1607 & $0.22^{\mathrm{a}}$ & $0.23^{\mathrm{a}}$ & $0.33^{\mathrm{a}}$ & $0.38^{\mathrm{b}}$ & $0.33^{\mathrm{a}}$ & & $0.25^{\mathrm{a}}$ & $0.25^{\mathrm{a}}$ & $0.26^{\mathrm{a}}$ & $0.39^{\mathrm{b}}$ & $0.31^{\mathrm{a}}$ & & $\mathrm{nm}$ & 0.37 & 0.34 & 1.25 & 0.42 & \\
\hline Acetophenone & 1660 & $\mathrm{nd}^{\mathrm{a}}$ & $0.23^{\mathrm{b}}$ & $\mathrm{nd}^{\mathrm{a}}$ & $\mathrm{nd}^{\mathrm{a}}$ & $0.61^{\mathrm{c}}$ & $\uparrow$ & $\mathrm{nd}^{\mathrm{a}}$ & $0.37^{\mathrm{b}}$ & $\mathrm{nd}^{\mathrm{a}}$ & $\mathrm{nd}^{\mathrm{a}}$ & $0.16^{\mathrm{b}}$ & & $\mathrm{nm}$ & $\mathrm{nd}^{\mathrm{a}}$ & $\mathrm{nd}^{\mathrm{a}}$ & $0.74^{\mathrm{b}}$ & $\mathrm{nd}^{\mathrm{a}}$ & \\
\hline 2-Tridecanone & 1819 & nd & nd & nd & nd & nd & & nd & nd & nd & nd & nd & & $\mathrm{nm}$ & $0.10^{\mathrm{a}}$ & $0.14^{\mathrm{a}}$ & $1.07^{\mathrm{b}}$ & $0.57^{\mathrm{b}}$ & $\uparrow$ \\
\hline \multicolumn{20}{|l|}{ Aldehydes } \\
\hline 2-Methylbutanal & 914 & nd & nd & nd & nd & nd & & $\mathrm{nd}^{\mathrm{a}}$ & $0.16^{\mathrm{b}}$ & $0.17^{\mathrm{b}}$ & $0.20^{\mathrm{b}}$ & $0.22^{\mathrm{b}}$ & $\uparrow$ & $\mathrm{nm}$ & $\mathrm{nd}^{\mathrm{a}}$ & $\mathrm{nd}^{\mathrm{a}}$ & $\mathrm{nd}^{\mathrm{a}}$ & $0.15^{\mathrm{b}}$ & $\uparrow$ \\
\hline Hexanal & 1099 & 1.10 & 1.83 & 0.89 & 1.44 & 2.54 & & 1.49 & 1.63 & 0.98 & 0.99 & 1.73 & & $\mathrm{~nm}$ & 1.70 & 2.30 & 2.66 & 3.27 & \\
\hline Nonanal & 1403 & 0.88 & 0.94 & 1.25 & 0.71 & 0.70 & & 0.67 & 0.82 & 0.98 & 1.21 & 1.13 & & $\mathrm{~nm}$ & $\mathrm{nd}^{\mathrm{a}}$ & $1.42^{\mathrm{b}}$ & $1.44^{\mathrm{b}}$ & $1.59^{\mathrm{b}}$ & $\uparrow$ \\
\hline Benzaldehyde & 1533 & $0.46^{\mathrm{a}}$ & $0.90^{\mathrm{a}}$ & $1.05^{\mathrm{a}}$ & $1.44^{\mathrm{b}}$ & $1.04^{\mathrm{a}}$ & & 0.65 & 1.23 & 0.61 & 1.19 & 0.98 & & $\mathrm{~nm}$ & 0.94 & 1.16 & 1.13 & 1.28 & \\
\hline \multicolumn{20}{|l|}{ Sulphides } \\
\hline Dimethyldisulphide & 1085 & nd & 0.02 & 0.02 & 0.04 & 0.04 & & 0.01 & 0.02 & 0.01 & 0.04 & 0.04 & & $\mathrm{~nm}$ & 0.03 & 0.03 & 0.02 & 0.03 & \\
\hline Dimethylsulfone & 1910 & $0.96^{\mathrm{a}}$ & $0.60^{\mathrm{a}}$ & $0.90^{\mathrm{a}}$ & $1.46^{\mathrm{b}}$ & $0.87^{\mathrm{a}}$ & & 1.41 & 0.86 & 1.92 & 0.84 & 1.89 & & $\mathrm{~nm}$ & 2.29 & 1.34 & 0.99 & 2.18 & \\
\hline \multicolumn{20}{|l|}{ Carboxylic acids } \\
\hline Butanoic acid $^{2}$ & 1689 & $\mathrm{nd}^{3}$ & nd & nd & nd & nd & & $\mathrm{nd}^{\mathrm{a}}$ & $0.21^{\mathrm{a}}$ & $0.60^{\mathrm{b}}$ & $0.19^{\mathrm{a}}$ & $\mathrm{nd}^{\mathrm{a}}$ & & $\mathrm{nm}$ & nd & nd & nd & nd & \\
\hline Hexanoic acid & 1900 & 0.35 & 0.34 & 0.87 & 0.72 & 0.35 & & 0.72 & 0.92 & 1.27 & 0.64 & 0.78 & & $\mathrm{~nm}$ & 0.80 & 1.00 & 1.90 & 0.51 & \\
\hline Octanoic acid & 2144 & $0.69^{\mathrm{a}}$ & $0.93^{\mathrm{a}, \mathrm{b}}$ & $0.85^{\mathrm{a}}$ & $1.75^{\mathrm{b}}$ & $0.98^{\mathrm{a}, \mathrm{b}}$ & $\uparrow$ & 1.38 & 2.10 & 1.64 & 1.39 & 1.55 & & $\mathrm{~nm}$ & 1.12 & 1.50 & 1.85 & 1.04 & \\
\hline Nonanoic acid & 2215 & 0.69 & 0.96 & 1.09 & 1.20 & 0.92 & & 1.57 & 1.41 & 0.48 & 0.83 & 1.30 & & $\mathrm{~nm}$ & 0.93 & 0.85 & 0.98 & 0.49 & \\
\hline Decanoic acid & 2307 & $0.41^{\mathrm{a}}$ & $0.63^{\mathrm{a}, \mathrm{b}}$ & $0.79^{\mathrm{b}}$ & $0.77^{\mathrm{b}}$ & $1.21^{\mathrm{c}}$ & $\uparrow$ & 0.68 & 0.98 & 1.10 & 1.04 & 2.09 & & $\mathrm{~nm}$ & 0.86 & 0.74 & 0.65 & 0.86 & \\
\hline \multicolumn{20}{|l|}{ Others } \\
\hline Butyl-cyclohexane & 1081 & nd & nd & nd & nd & nd & & nd & nd & nd & nd & nd & & $\mathrm{nm}$ & 0.72 & 0.79 & 0.91 & 0.93 & \\
\hline Ethyl-benzene & 1136 & nd & nd & nd & nd & nd & & $\mathrm{nd}^{\mathrm{a}}$ & $\mathrm{nd}^{\mathrm{a}}$ & $\mathrm{nd}^{\mathrm{a}}$ & $\mathrm{nd}^{\mathrm{a}}$ & $0.90^{\mathrm{b}}$ & $\uparrow$ & $\mathrm{nm}$ & nd & nd & nd & nd & \\
\hline DL-Limonene & 1210 & nd & nd & nd & 4.46 & 0.26 & & $\mathrm{nd}^{\mathrm{a}}$ & $\mathrm{nd}^{\mathrm{a}}$ & $\mathrm{nd}^{\mathrm{a}}$ & $\mathrm{nd}^{\mathrm{a}}$ & $2.42^{\mathrm{b}}$ & $\uparrow$ & $\mathrm{nm}$ & nd & nd & nd & nd & \\
\hline Junipene & 1568 & $\mathrm{nd}^{\mathrm{a}}$ & $0.22^{\mathrm{b}}$ & $0.23^{\mathrm{b}}$ & $0.25^{\mathrm{b}}$ & $0.23^{\mathrm{b}}$ & & nd & nd & nd & nd & nd & & $\mathrm{nm}$ & $0.91^{\mathrm{a}}$ & $\mathrm{nd}^{\mathrm{b}}$ & $0.69^{\mathrm{a}}$ & $0.93^{\mathrm{a}}$ & \\
\hline Butyrolactone & 1637 & $0.33^{\mathrm{a}}$ & $1.41^{\mathrm{b}}$ & $0.39^{\mathrm{a}}$ & $0.42^{\mathrm{a}}$ & $0.88^{\mathrm{a}}$ & & $0.40^{\mathrm{a}}$ & $1.89^{\mathrm{b}}$ & $0.53^{\mathrm{a}}$ & $0.39^{\mathrm{a}}$ & $0.68^{\mathrm{a}}$ & & $\mathrm{nm}$ & 0.63 & 0.42 & 0.99 & 0.33 & \\
\hline Phenol & 2020 & 0.21 & 0.17 & 0.22 & 0.23 & 0.18 & & 0.19 & 0.23 & 0.20 & 0.17 & 0.22 & & $\mathrm{~nm}$ & $0.30^{\mathrm{a}}$ & $0.26^{\mathrm{a}}$ & $0.15^{\mathrm{b}}$ & $0.23^{\mathrm{a}}$ & \\
\hline p-Cresol & 2095 & 0.10 & 0.06 & 0.12 & 0.11 & 0.08 & & $0.09^{\mathrm{a}}$ & $0.08^{\mathrm{a}}$ & $\mathrm{nd}^{\mathrm{b}}$ & $n d^{b}$ & $\mathrm{nd}^{\mathrm{b}}$ & $\downarrow$ & $\mathrm{nm}$ & $\mathrm{nd}^{\mathrm{a}}$ & $0.12^{\mathrm{b}}$ & $\mathrm{nd}^{\mathrm{a}}$ & $\mathrm{nd}^{\mathrm{a}}$ & \\
\hline m-Cresol & 2104 & 0.47 & 0.29 & 0.47 & 0.50 & 0.39 & & 0.37 & 0.40 & 0.42 & 0.41 & 0.45 & & $\mathrm{~nm}$ & 0.60 & 0.55 & 0.45 & 0.56 & \\
\hline$\delta$-Decalactone & 2199 & $\mathrm{nd}^{\mathrm{a}}$ & $0.15^{\mathrm{b}}$ & $0.12^{\mathrm{b}}$ & $0.09^{\mathrm{b}}$ & $0.10^{\mathrm{b}}$ & & $0.10^{\mathrm{a}}$ & $0.23^{\mathrm{b}}$ & $0.13^{\mathrm{a}}$ & $0.07^{\mathrm{a}}$ & $0.08^{\mathrm{a}}$ & & $\mathrm{nm}$ & $0.24^{\mathrm{a}}$ & $0.18^{\mathrm{a}}$ & $0.13^{\mathrm{a}}$ & $0.05^{\mathrm{b}}$ & $\downarrow$ \\
\hline
\end{tabular}

a Storage ( $0-120$ days) was at $20^{\circ} \mathrm{C}$ in a climate chamber under controlled conditions. RI linear retention index Compounds tentatively identified matching the NIST-2014/Wiley 7.0 libraries Values ( $\mu \mathrm{g}$ IS $\left.\mathrm{L}^{-1}\right)$ reported as mean of three measurements $(\mathrm{n}=3$; nd, not detected; $\mathrm{nm}$, not measured); means within each commercial UHT HLM samples with different superscript letters differ significantly $(P<0.05)$. Arrows indicate significant trends $(P<$ 0.05 ) between either 0 days (for HLM1, HLM2) or 30 days (for HLM3) and 120 days of storage: $\uparrow$, increase; $\downarrow$, decrease. 
(increase/decrease) in the volatile profiles. The results showed temporal changes of some VOCs during storage (Fig. 4). As previously reported for UHT milk, ketones were the most abundant class in terms of number of identified compounds (Dursun, Güler, \& Şekerli, 2017). The increase of methyl-ketones in UHT HLM was previously associated with "cooked taste" and "stale flavour" (Troise et al., 2016). In our study, a significant increase of methylketones concentration over time was registered in line with previous literature (Jansson et al., 2014a). 2-Heptanone was present at the highest concentrations, ranging from $9.61 \mu \mathrm{g}$ IS $\mathrm{L}^{-1}$ to $14.85 \mu \mathrm{g}$ IS L $^{-1}$ at the end of the storage depending on the sample. Moreover, the results showed different concentrations of methyl-ketones in the three commercial samples at the different time of measurement. Remarkably, HLM3 (the sample produced by "in pack" production system) was the commercial hydrolysed-lactose milk significantly richer in 2-butanone (Fig. 4a), 2-pentanone (Fig. 4b) and 2-heptanone (Fig. 4c) after 120 days of storage.

Lactones tended to decrease during storage, for all three samples. The results of the ANOVA showed a significant temporal decrease of $\delta$-decalactone between 30 and 120 days of storage in HLM3. Reasonably, the formation of lactones is considered an index of the heating applied during processing, and the decrease of $\delta$ decalactone during storage was expected because of the polymerisation during milk storage (Loney \& Bassette, 1971). Some aldehydes increased during storage, while others did not. The concentration of benzaldehyde remained constant in all the three samples, in agreement with previous reports (Jansson et al., 2014c; Troise et al., 2016).
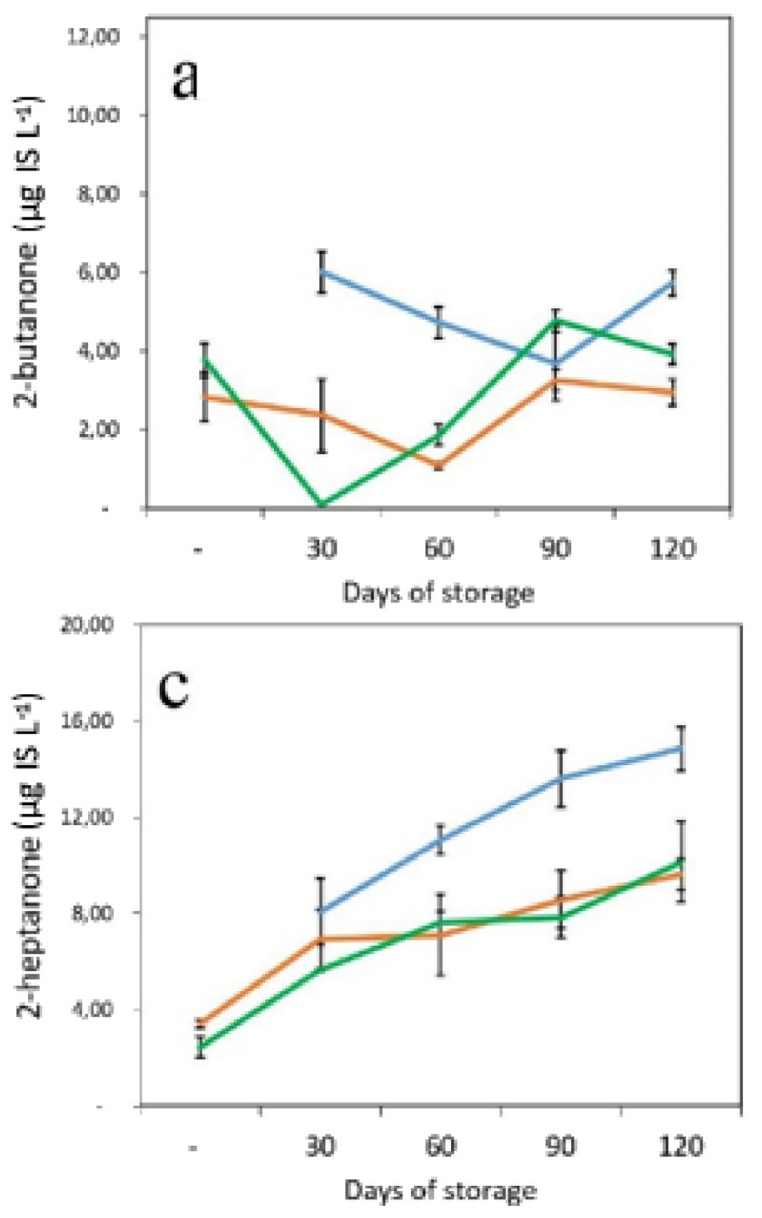

2-Methylbutanal followed particular trends depending on the commercial HLM sample. It is important to mention that, with the polar phase we used for the chromatographic separation, 2methylbutanal and 3-methylbutanal peaks are not completely resolved (their retention indices are $914 \pm 8$ and $918 \pm 7$ respectively according to MS-NIST library). Consequently, external standards were injected to distinguish the two peaks. This analysis confirmed the presence of solely the 2-methylbutanal. As illustrated in Fig. 4d, in HLM1 2-methylbutanal was not detected throughout storage. In contrast, it appeared in HLM3 after 120 days, while its tendency in HLM2 was to progressively increase over time. While the trend of the 2-methylbutanal in HLM3 (produced by "in pack" system and packed in paperboard carton) was previously reported (Troise et al., 2016) on other commercial samples manufactured with the same method, the presence of 2-methylbutanal already after 30 days of storage in HLM2 (produced by "in batch" system and packed in HDPE) was difficult to interpret. A possible explanation could be the milk variability existing between the tested commercial samples.

Dimethyl disulphide (DMDS) was detected in low concentration and at comparable level in all the three HLMs. The absence of significant changes in concentration of dimethyl sulfone, which can be originated from the oxidation of dimethyl disulphide, confirmed the results (Al-Attabi, D'Arcy, \& Deeth, 2009). The results are in agreement with Jansson et al. (2017). Volatile sulphur compounds contribute to cooked/sulphurous flavour of UHT milk, but their estimation is extremely challenging due to low concentration and high volatility (Al-Attabi, D'Arcy, \& Deeth, 2014).
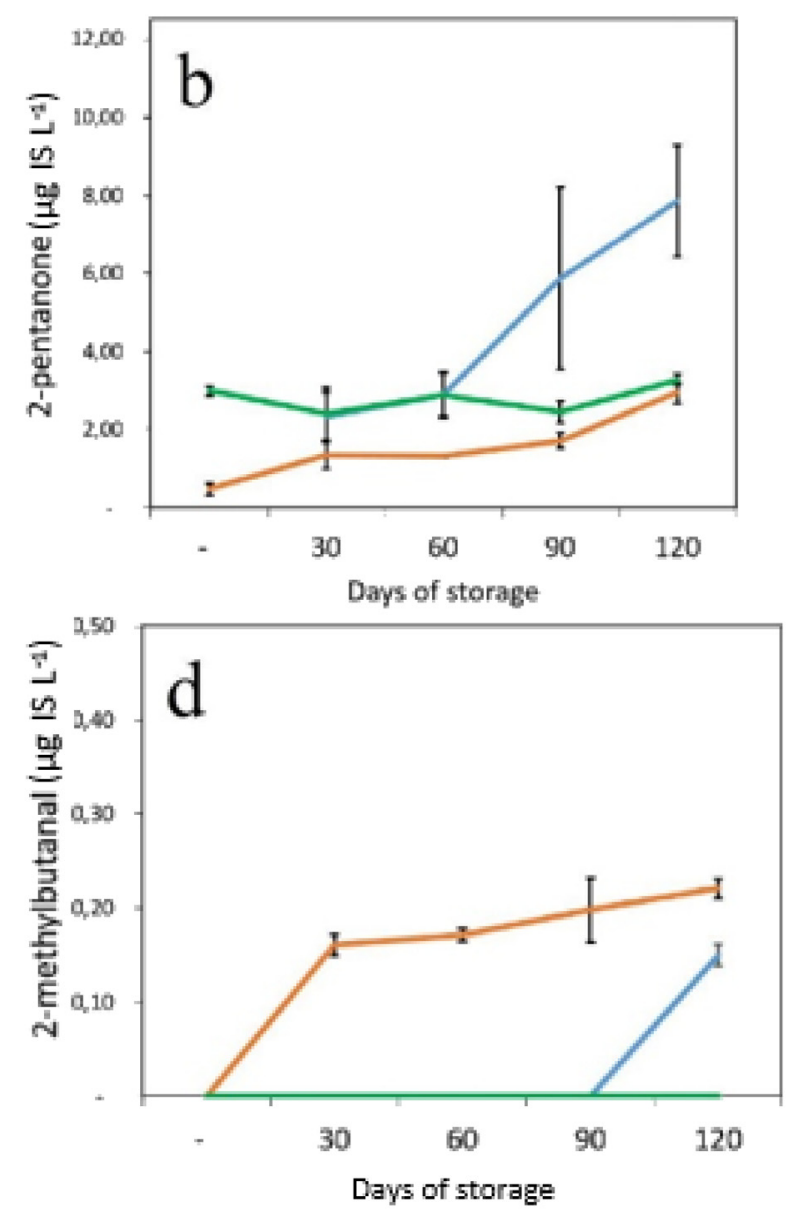

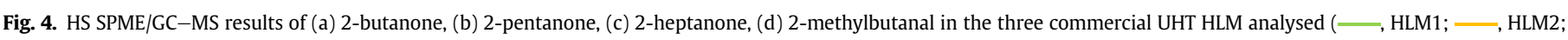
, HLM3) during storage at $20^{\circ} \mathrm{C}$ for 120 days. 
The three mentioned aldehydes (benzaldehyde, 2-methylbutanal and DMDS) are compounds formed by the Strecker degradation, a reaction pathway previously associated to the proteolytic side activity of the lactase in the milk during storage (Jansson et al., 2019; Troise et al., 2016). As Maillard reaction creates the precursors (Rizzi, 1999), the detection of these compounds might indicate its progress in the analysed samples. Benzaldehyde is formed by oxidation of phenylacetaldehyde (a Strecker aldehyde coming from phenylalanine), 2-methylbutanal is a degradation product of isoleucine, whereas DMDS is produced from methionine (Al-Attabi et al., 2014; Fong \& Yaylayan, 2008; Jansson et al., 2017). In this context, the different evolution of in 2methylbutanal in the commercial HLMs during storage further indicated that the applied HS SPME methodology was capable to reveal reaction pathways important for the definition of the final sensory quality of hydrolysed-lactose milk.

\section{Conclusions}

The present study supported the application of the HS-SPME/ GC-MS technique as handy and efficient tool for extracting volatiles from HLMs in different scenarios. Applying a $2^{3}$ full factorial design, optimised SPME conditions were selected and successfully applied to explore possible differences in the volatile profiles of three commercial UHT HLM, as well as among three typical steps of HLM manufacturing.

Since UHT HLM manufactured for this study were produced under controlled processing conditions, the observed differences can be attributed to specific factors. HLMs were discriminated based on their relative VOCs content both during production and storage. Hydrolysis of lactose during "in batch" production did not affect the product profile significantly, while most of the volatiles were formed after UHT treatment. This result is of particular interest if we think that backside enzymatic activity may not be the only unwanted characteristic of the commercial lactase. Lactase preparations contain also different levels of volatiles compounds (unpublished data). Interestingly, the results showed that when lactase was added into the milk tank, any volatile possibly present in the preparation was covered by the "volatilome" of the milk, probably due to a dilution effect. Because of a lack of technical information about the lactase preparation employed, the discussion of this particular aspect is, however, limited.

The causes determining the differentiation of the three commercial HLMs over storage were several. Looking at the intensity and the temporal evolution of specific compounds, stronger development of VOCs occurred in HLM3, which was produced by the "in pack" system. Nevertheless, additional variables (e.g., lactase purity, packaging, batch variability) may have participated to the encountered results and deserves more attention in future studies. Overall, HS-SPME provided excellent extraction performance. Semi-quantitative analysis highlighted methyl-ketones and Strecker aldehydes as markers differentiating the commercial UHT HLM samples. Eventually, following the changes in the VOCs profiles of UHT HLM during production and shelf-life was proved useful to investigate the reaction pathways underlining the final product quality.

\section{Acknowledgements}

The present study is part of the Ph.D. project of R. B. financially supported by Wageningen University, Edmund Mach Foundation, and University of Naples Federico II. This research did not receive any specific grant from funding agencies in the public, commercial, or not-for-profit sectors.

\section{Appendix A. Supplementary data}

Supplementary data to this article can be found online at https://doi.org/10.1016/j.idairyj.2020.104715.

\section{References}

Al-Attabi, Z., D'Arcy, B. R., \& Deeth, H. (2014). Volatile sulfur compounds in pasteurised and UHT milk during storage. Dairy Science \& Technology, 94, 241-253.

Al-Attabi, Z., D'Arcy, B. R., \& Deeth, H. C. (2009). Volatile sulphur compounds in UHT milk. Critical Reviews in Food Science and Nutrition, 49, 28-47.

Aprea, E., Gasperi, F., Betta, E., Sani, G., \& Cantini, C. (2018). Variability in volatile compounds from lipoxygenase pathway in extra virgin olive oils from tuscan olive germoplasm by quantitative SPME/GC-MS. Journal of Mass Spectrometry, 53, 824-832.

Aprea, E., Gika, H., Carlin, S., Theodoridis, G., Vrhovsek, U., \& Mattivi, F. (2011) Metabolite profiling on apple volatile content based on solid phase microextraction and gas-chromatography time of flight mass spectrometry. Journal of Chromatography A, 1218, 4517-4524.

Aprea, E., Romanzin, A., Corazzin, M., Favotto, S., Betta, E., Gasperi, F., et al. (2016). Effects of grazing cow diet on volatile compounds as well as physicochemical and sensory characteristics of 12-month-ripened Montasio cheese. Journal of Dairy Science, 99, 6180-6190.

Bergamaschi, M., Aprea, E., Betta, E., Biasioli, F., Cipolat-Gotet, C., Cecchinato, A. et al. (2015). Effects of dairy system, herd within dairy system, and individual cow characteristics on the volatile organic compound profile of ripened model cheeses. Journal of Dairy Science, 98, 2183-2196.

Condurso, C., Verzera, A., Romeo, V., Ziino, M., \& Conte, F. (2008). Solid-phase microextraction and gas chromatography mass spectrometry analysis of dairy product volatiles for the determination of shelf-life. International Dairy Journal, $18,819-825$.

Contarini, G., Povolo, M., Leardi, R., Toppino, P. M., Lattiero caseario, I. S., Lombardo, V., et al. (1997). Influence of heat treatment on the volatile compounds of milk. Journal of Agricultural and Food Chemistry, 45, 3171-3177.

Corgneau, M., Scher, J., Ritie-Pertusa, L., Le, D.t. l., Petit, J., Nikolova, Y., et al. (2017). Recent advances on lactose intolerance: Tolerance thresholds and currently available answers. Critical Reviews in Food Science and Nutrition, 57, 3344-3356.

Dekker, P. J. T., Koenders, D., \& Bruins, M. J. (2019). Lactose-free dairy products: Market developments, production, nutrition and health benefits. Nutrients, 11 551.

Dursun, A., Güler, Z., \& Sekerli, Y. E. (2017). Characterization of volatile compounds and organic acids in ultra-high-temperature milk packaged in tetra brik cartons. International Journal of Food Properties, 20, 1511-1521.

Endrizzi, I., Fabris, A., Biasioli, F., Aprea, E., Franciosi, E., Poznanski, E., et al. (2012). The effect of milk collection and storage conditions on the final quality of Trentingrana cheese: Sensory and instrumental evaluation. International Dairy Journal, 23, 105-114.

Evangelisti, F., Calcagno, C., Nardi, S., \& Zunin, P. (1999). Deterioration of protein fraction by Maillard reaction in dietetic milks. Journal of Dairy Research, 66, 237-243.

Fiorini, D., Pacetti, D., Gabbianelli, R., Gabrielli, S., \& Ballini, R. (2015). A salting out system for improving the efficiency of the headspace solid-phase microextraction of short and medium chain free fatty acids. Journal of Chromatography $A, 1409,282-287$.

Fong, L. C., \& Yaylayan, V. A. (2008). Model studies on the oxygen-induced formation of benzaldehyde from phenylacetaldehyde using pyrolysis GC-MS and FTIR. Journal of Agricultural and Food Chemistry, 56, 10697-10704.

González-Córdova, A. F., \& Vallejo-Cordoba, B. (2001). Quantitative determination of short-chain free fatty acids in milk using solid-phase microextraction and gas chromatography. Journal of Agricultural and Food Chemistry, 49, 4603-4608.

Harju, M., Kallioinen, H., \& Tossavainen, O. (2012). Lactose hydrolysis and other conversions in dairy products: Technological aspects. International Dairy Journal, 22, 104-109.

Ingram, C. J. E., Mulcare, C. A., Itan, Y., Thomas, M. G., \& Swallow, D. M. (2009). Lactose digestion and the evolutionary genetics of lactase persistence. Human Genetics, 124, 579-591.

Jansson, T., Clausen, M. R., Sundekilde, U. K., Eggers, N., Nyegaard, S., Larsen, L. B., et al. (2014a). Lactose-hydrolyzed milk is more prone to chemical changes during storage than conventional ultra-high-temperature (UHT) milk. Journal of Agricultural and Food Chemistry, 62, 7886-7896.

Jansson, T., Jensen, S., Eggers, N., Clausen, M. R., Larsen, L. B., Ray, C., et al. (2014c). Volatile component profiles of conventional and lactose-hydrolyzed UHT milka dynamic headspace gas chromatography-mass spectrometry study. Dairy Science \& Technology, 94, 311-325.

Jansson, T., Jensen, H. B., Sundekilde, U. K., Clausen, M. R., Eggers, N., Larsen, L. B. et al. (2014b). Chemical and proteolysis-derived changes during long-term storage of lactose-hydrolyzed ultrahigh-temperature (UHT) milk. Journal of Agricultural and Food Chemistry, 62, 11270-11278.

Jansson, T., Rauh, V., Danielsen, B. P., Poojary, M. M., Waehrens, S. S., Bredie, W. L. P. et al. (2017). Green tea polyphenols decrease Strecker aldehydes and bind to proteins in lactose-hydrolyzed UHT milk. Journal of Agricultural and Food Chemistry, 65, 10550-10561. 
Jansson, T., Waehrens, S. S., Rauh, V., Danielsen, B. P., Sørensen, J., Bredie, W. L. P., et al. (2019). Effect of green tea catechins on physical stability and sensory quality of lactose-reduced UHT milk during storage for one year. International Dairy Journal, 95, 25-34.

Jelen, P., \& Tossavainen, O. (2003). Low lactose and lactose-free milk and dairy products - pprospects, technologies and applications. Australian Journal of Dairy Technology, 58, 161-165.

Leonardi, M., Gerbault, P., Thomas, M. G., \& Burger, J. (2012). The evolution of lactase persistence in Europe. A synthesis of archaeological and genetic evidence. International Dairy Journal, 22, 88-97.

Loney, B. E., \& Bassette, R. (1971). Changes in free fatty acids and lactones in sterile concentrated milk during storage. Journal of Dairy Science, 54, 343-348.

Marsili, R. T. (1999). SPME - MS - MVA as an electronic nose for the study of offflavors in milk. Journal of Agricultural and Food Chemistry, 47, 648-654.

Nielsen, S. D., Zhao, D., Le, T. T., Rauh, V., Sørensen, J., Andersen, H. J., et al. (2018). Proteolytic side-activity of lactase preparations. International Dairy Journal, 78, 159-168.

Povolo, M., \& Contarini, G. (2003). Comparison of solid-phase microextraction and purge-and-trap methods for the analysis of the volatile fraction of butter. Journal of Chromatography A, 985, 117-125.
Rizzi, G. P. (1999). The Strecker degradation and its contribution to food flavor. In R. Teranishi, E. L. Wick, \& I. Hornstein (Eds.), Flavor chemistry (pp. 335-342). Boston, MA, USA: Springer.

Tossavainen, O., \& Kallioinen, H. (2007). Proteolytic changes in lactose hydrolysed UHT milks during storage. Milchwissenschaft, 62, 410-415.

Troise, A. D., Bandini, E., De Donno, R., Meijer, G., Trezzi, M., \& Fogliano, V. (2016). The quality of low lactose milk is affected by the side proteolytic activity of the lactase used in the production process. Food Research International, 89, $514-525$.

Valero, E., Villamiel, M., Miralles, B., Sanz, J., \& Martínez-Castro, I. (2001). Changes in flavour and volatile components during storage of whole and skimmed UHT milk. Food Chemistry, 72, 51-58.

Vazquez-Landaverde, P. A., Velazquez, G., Torres, J. A., \& Oian, M. C. (2005). Quantitative determination of thermally derived off-flavor compounds in milk using solid-phase microextraction and gas chromatography. Journal of Dairy Science, $88,3764-3772$.

Yang, X., \& Peppard, T. (1994). Solid-phase microextraction for flavor analysis. Journal of Agricultural and Food Chemistry, 42, 1925-1930. 